\title{
An Intercultural Immersion: Personal, Professional, and Cultural Expectations of Student Participants
}

Julie Maakrun

University of Notre Dame, Australia

Sean Kearney

University of Notre Dame, Australia 


\title{
An Intercultural Immersion: Personal, Professional, and Cultural Expectations of Student Participants
}

\author{
Julie Maakrun \\ Sean Kearney \\ University of Notre Dame, Australia
}

\begin{abstract}
Increasing global migration across geographical, linguistic, and cultural borders has resulted in Australian classrooms being more culturally and linguistically diverse. For preservice teachers, it is of critical importance that they, through experiences, develop a global worldview and have the knowledge, skills, and understanding to effectively respond to cultural diversity, and, in doing so, recognize their ability to be agents of social change. As such, preservice teacher education programs are capitalizing on ways to enhance preservice teachers' ability to appropriately respond to cultural diversity. Intercultural immersion programs allow opportunities for students to be embedded in the breadth and depth of human experience so students will better understand themselves and the "cultural other." This particular program involved 20 Australian preservice teachers in a 3-week immersion in Kenya. This article explores the expectations leading into the program as a means to better understand participants' perceptions prior to their departure in order that the entire immersion journey may be fully documented. Analysis of survey responses, semistructured focus group interviews, and written applications revealed expectations that fell into three categories: personal, professional, and cultural.
\end{abstract}

Keywords: altruism, culture, immersion, preservice teacher education, relationships

\section{Una inmersión intercultural: Expectativas personales, profesionales y culturales de estudiantes participantes}

El aumento de la migración global a través de fronteras geográficas, lingüísticas y culturales ha dado como resultado que las escuelas australianas sean cada vez más diversas, tanto desde el punto de vista cultural como lingüístico. Este tipo de experiencias es de vital importancia para que los docentes en formación desarrollen una perspectiva global, adquiriendo conocimiento, competencias y capacidad de razonamiento que les permitan responder eficazmente a la diversidad cultural, y que, de esta manera, reconozcan sus aptitudes como agentes del cambio social. Asimismo, estos programas de formación docente están aprovechando las formas de mejorar la capacidad de los profesores para responder adecuadamente a la diversidad cultural. Los programas de inmersión intercultural ofrecen a los estudiantes la oportunidad de integrarse en extensión y profundidad a la experiencia humana, en aras de una mejor comprensión de sí mismos y de la "cultura del otro" Este programa en específico involucró a 20 profesores australianos en una inmersión total de tres semanas en Kenia. Este artículo analiza las expectativas del programa como medio para comprender mejor las percepciones de los participantes antes del viaje y así poder documentar a cabalidad la experiencia de inmersión. Las respuestas a las encuestas, las entrevistas semiestructuradas a grupos focales y las solicitudes por escrito revelaron que las expectativas se dividían en tres categorías: personal, profesional y cultural.

Palabras clave: altruismo, cultura, inmersión, educación del personal docente, relaciones de colaboración

Editors' Note: Translation by Yamilet Hernandez Department of English and Foreign Languages 
Immersion programs are embedded within the scope, volume, and complexity of the variety of activities offered within higher education institutions (Altbach \& Knight, 2007). These kinds of programs, which involve students volunteering, have received increased attention over recent years (Clayton et al., 2012; Mooney \& Edwards, 2001). Increased attention is in part the result of these programs affording institutions the mechanism to provide opportunities to students to foster graduate attributes and build dispositions, skills, and competencies (Curtis \& Ledgerwood, 2018; Hill et al., 2016). Cultural immersion programs place participants in a cultural context different from their own, where they often live in a homestay and provide some form of assistance within the community.

Immersion programs as an educational approach or pedagogy can be a powerful vehicle to enhance students' global mindedness and awareness of social issues. Such programs allow for the development of a greater moral and ethical sense (Cole, 1994; Cooper, 2017). Intercultural immersion programs are those that intentionally cross a cultural boundary and integrate cultural learning of self and others (Campus Compact, 2002). Thus, international activities through which students' cross cultural boundaries allow participants to recognize the importance of culture, its connection to community, and the relationships among language, culture, and practice (Roose, 2001). Butin (2003) suggested that the experience of engaging with the "cultural other" allows students to better understand, respect, and engage with the cultural plurality of diverse societies. This kind of cultural perspective "privileges the affective, ethical, and formative aspects of immersions, concerned with linking these experiential components to local, national and international issues" (Butin, 2003, p. 1681).

Increasing global interconnectedness has allowed increasing engagement with diverse cultures, beliefs, and events that transform understandings of the world (Bamber et al., 2018). One of the many developmental outcomes of these types of global activities is intercultural competence (Meyer-Lee \& Evans, 2007). Intercultural competence requires a level of cultural knowledge, values, and dispositions to act in an informed manner and to engage in effective intergroup communication so as to foster and enable community growth across social, cultural, political, environmental, geographic, and economic boundaries (Whaley \& Davis, 2007).

Australian society, like many others in our globalized world, is culturally diverse. One in five Australians has a language background other than English, with more than 300 separately identified languages. Further, approximately $49 \%$ of all Australians were either born overseas or had at least one parent who was born overseas (Australian Bureau of Statistics, 2016). In 2018, more than 280,000 students enrolled in New South Wales government schools identified as having a language other than English, with a total of 239 languages spoken (Centre for Education Statistics and Evaluation, 2018). Undergraduate teacher education programs within Australia are being contextualized and transformed as they consolidate a set of national professional teaching standards (Australian Institute for Teaching and School Leadership, 2011; Darling-Harmond, 2010; Zeichner, 2010). Reflected within these standards is the key tenet of developing greater intercultural competence. It has become critical for teachers to have the requisite pedagogical knowledge and skills to meet the increasing cultural diversity of students (Gay, 2010).

A challenge for teacher education providers is to understand how preservice teacher education programs can be tailored to address cultural diversity that can assist in the preparation of culturally responsive teachers (Siwatu, 2007; Villegas \& Lucas, 2002). Culturally responsive teachers are able to acknowledge, respond to, and utilize pedagogy that ensures equity of educational outcomes is upheld for students from all cultures. Thus, cultural responsivity requires teachers to learn and teach through the lens of global mindedness, which includes the capacity to teach students how their actions and the actions of others affect people in all parts of the world, encouraging students to be agents of change driven by their own critical thinking and actions (Chareka et al., 2010). As teacher education students will increasingly be working in a globally connected world, one challenge, as suggested by Mangram and Watson (2011), is whether they will they be adequately prepared to respond. This challenge is further supported by Miller (2015), who contended that preservice teacher education in Australia lacked training of competencies and also lacked the development of understanding of the cultural and social aspects of diverse classrooms. 
Research data resulting from interviews conducted with preservice teachers by Maloney and Saltmarsh (2016) found that more than 50\% expressed feeling unprepared to teach in culturally diverse classrooms.

The role that teacher educators play is crucial to preparing young teachers to respond to the challenges of diversity, equity, and global interconnectedness. McCormack and O'Flaherty (2010) further suggested that internationally only a few preservice teacher education programs provided a global perspective of education. Maloney and Saltmarsh (2016) argued that "Pre-service teacher education programs must provide a dynamic and individually stimulating educational experience with the development of new strategies to build critical enquiry and to stimulate individual responsibility for social justice in education" (p. 88). Further, traditional teacher training in Western countries has failed to adequately prepare teachers to critically "re-examine their own positions of privilege and cultural superiority" (Mangram \& Watson, 2011, p. 97) or question how their own identity has been constructed.

For preservice teachers, intercultural immersion programs can allow for the acquisition of new understandings about life, culture, self, and others and have the potential to lead to changes in classroom practices (Walters et al., 2009). Given this potential, coupled with the personal and professional outcomes of immersion programs, a detailed consideration of the expectations of students leading into such programs would allow for a holistic understanding of the journey from participants' expectations to their in-country experiences and finally the reflections of the entire immersion experience, prior to, during, and post.

Curtis and Ledgerwood (2018) contended that when preparing international educational opportunities for students, educators should have a clear understanding of participants' motivations and expectations. As such, his paper positioned participants' expectations of their immersion, prior to departure, through the lens of motivation. Two constructs that often appear in motivation literature, altruism and egoism, can be used to analyze participants' expectations. Expectations, like motivations, is multifaceted and complex (Fitch, 1987; Martin, 1994; Parnell, 1990). Finkelstein et al. (2005) postulated that some people want to help others for altruistic reasons whilst others may be egoistically driven. In simple terms, if placed within a paradigm, egoism asserts that motives, and for the purposes of this article, expectations are self-seeking whilst altruism maintains that expectations are primarily driven by a desire to help others (Martin, 1994). The sustainability of programs that rely on volunteer participation is highly dependent on appropriately matching the motivational concerns of the participants with contexts that can satisfy the stated outcomes of the intended program (Clary \& Snyder, 1999). Underlying motives to volunteer for such programs may initially be motivated by altruism, but some research suggests that more self-seeking motivations are important for continued participation (Ryan et al., 2001). Shye (2010) classified the causes for volunteering (and of giving, in general) into three classes: demographic antecedents, which include the personal resources required to volunteer; motivations, which are more specific and necessary for individuals to want volunteer; and circumstances - the opportunities available, which facilitate and prompt volunteering to actually take place.

The notion of helping the other, or the expectation of wanting to help the other, elicits a degree of empathic concern, which, when viewed through an affective lens, is one that promotes selfless motivation (Batson, 1998). Such involvement is manifested in the contribution of time, energy, and resources, with the sole intention of helping others. For Australians, the notion of helping others through donating money or volunteering is perhaps culturally embedded. In 2018, Australia ranked second out of 146 countries in the Charities Aid Foundation World Giving Index. This index reports on insights into the nature of giving and of global generosity. Batson (1997) postulated that one should differentiate whether the motivation (or expectation) is egoistic or altruistic; and he asserted that even if both types are present, it is the ultimate goal that defines whether it is egoistic or altruistic.

As altruism is often cited as a principal motivation to volunteer, research by Gage and Thapa (2012) suggests that many people seek out opportunities to provide service to others as a way to satisfy their own needs. Embedded within social exchange theory, which contends that all interactions are based on an exchange of costs, altruism results from what one gives and egoism results from what one receives in return (Phillips, 1982). Whilst some researchers disagree that an exchange can be of equal benefit (Eby, 1998; Stoecker et al.,2009), others such as Musick and Wilson (2007) believe that serving others is 
mutually beneficial to the donor and the recipient. Related to the construct of social exchange is social obligation. Social obligation is defined as the goal of repaying something back to society. A study of college students by Fitch (1987) classified motivations for volunteering into egoistic, altruistic, and social obligation. Egoistic reasons included the sense of satisfaction in helping others; altruistic reasons included being concerned about others who are less fortunate; and social obligation included both the desire to give back and the hope that, if the need arose, others would do the same for the givers. Within both social exchange and social obligation theory is the expectation that if one gives, one will receive. Expectancy theory is often applied to the motivation of work and asserts that individuals will be motivated to the extent to which they believe their behavior will lead to the outcomes they personally desire (Hoy \& Miskel, 1991; Miller \& Grush, 1988; Steers \& Porter, 1983). Three factors that affect behavior are (1) the need for achievement, and the resultant sense of pride in the accomplishment; (2) the need for affiliation with others; and (3) the need for influence or impact on others. Mounter (1985) contended that all individuals are motivated by these needs but that the degree of motivation is influenced by both the intensity of the needs and the degree of expected satisfaction.

\section{Methodology}

The research design was situated within an interpretive social constructivist paradigm. The advantage of working within this paradigm is that it allowed for multiple representations of participant perceptions contained within their individual frames of reference and thus produced qualitative evidence to describe these perceptions adequately. The researchers are positioned within the study as both faculty academics and participants in the immersion. This positioning was purposeful as it allowed interaction with the participants so as to explore and build a detailed understanding of experiences of cultural competence within an international immersion program. Quantitative researchers may argue that qualitative researchers should remain objective; the counterargument is that researcher subjectivity is advantageous as it seeks to gain insider knowledge in order to accurately report the lived experiences of participants. The choice of data collection methods to present the findings is contextualized and thus all "exist within and are the products of the same contextual web" (Zimmer, 2006, p. 315).

In this study, the researcher is "the main instrument for data gathering, analysis, interpretation, and representation" (Merriam, 2002, p. 5). This characteristic of qualitative research is contentious; however, as mentioned above, this positioning was considered necessary because it allowed for a more comprehensive understanding of the total immersion experience. Given the relatively small number of participants, a clear limitation of this study is that the findings cannot be generalized to the larger population.

\section{Participants}

This particular study centers on a group of 20 preservice teacher education students who elected to participate voluntarily in an intercultural immersion program in Kenya. These 20 constitute a subset $(59 \%)$ of 34 preservice teacher education students at a private Catholic university in Sydney, Australia, who had volunteered to participate in the program. All students self-funded their participation in the immersion program, which was conducted outside of the parameters of an academic year. They were primary preservice teacher education students between 19 and 27 years of age; 18 of them were in their final two years of the four-year degree program. The majority of the participants were females (18 or 90\%).

Participants raised additional funds that were used to purchase school-based resources and materials, which were donated to the school community in Kenya. The school, Aberdare Ranges Primary, was founded in 2011 by the Australian-based not-for-profit organization named So They Can. 


\section{Data}

Data collected were personal statements, questionnaire responses, and responses to two semi-structured focus group interviews. A personal statement, which formed one section of the application to participate in the program, sought to elicit information about previous travel experience, volunteer work, personal motivation for applying, and what the applicant hoped to achieve by joining the program. Personal statements ranged in length from two paragraphs to one page. For the purposes of this article, the following two questions were included in the questionnaire:

(1) What expectations do you have of participating in the Kenya immersion?

(2) What are you most / least looking forward to as part of the Kenya immersion?

Two months prior to departure, two semi-structured focus group interviews were conducted. A total of 10 participants $(50 \%)$ elected to participate, each focus group consisting of five participants. These interviews sought to further engage participants in discussion emanating from questionnaire responses. Interviews were conducted by one of the researchers, averaged an hour in duration, and were audio recorded and transcribed. This dataset enabled the researcher to triangulate the data for internal validity and to better understand the participants' expectations of the immersion program. Personal statements were submitted by participants 6 months prior to departure; the questionnaire and the semi-structured focus group interviews were completed 3 months and 2 months, respectively, prior to departure.

\section{Data Analysis}

Reflective thematic analysis of the data (Braun \& Clark, 2019) was used to understand the expectations of the participants prior to their departure. The data were checked and rechecked before being coded and then categorized by personal, professional, and cultural expectations. Each dataset was analyzed separately and then were synthesized to determine emerging themes.

Table 1 is an extrapolation of findings from participants' personal statements as contained in the completed application forms, which relate to their expectations of the immersion program. Only codes that had three or more participant responses are indicated; codes with fewer than 3 responses were deemed reflective of an individual participant's perspective and not that of the collective group. Thus, discussion of the findings will be demonstrative of the responses of the participants collectively rather than individual responses.

Table 1

Participant Expectations (from Personal Statements in the Application)

\begin{tabular}{ll}
\hline Code & Participant (PS) \\
\hline Form a different perspective on life & $1,2,6,8,16,17$ \\
Being challenged & $3,9,6,13,14$ \\
Make a positive and or meaningful contribution & $3,7,11,14$ \\
Helping others & $3,4,7,16$ \\
A different cultural experience & $5,6,7,11,13,15,17,20$ \\
Inform me as a teacher and inform pedagogy & $1,5,8,14,17,19,20$ \\
Making a difference & $1,2,4,5,11,15,18,20$ \\
Appreciation and gratitude & $7,9,14$ \\
Privilege and responsibility & $4,16,18$ \\
Making a positive impact & $4,9,10,16$ \\
\hline
\end{tabular}


Table 2 presents findings from participants' responses to the pre-immersion questionnaire related to their expectations of the immersion program. Each code is represented by the individual participant (PS) identifier (number). Similar to the procedure with the completed application forms, only codes that had three or more participant responses are reported.

Table 2

Participant Expectations (from Pre-Immersion Questionnaire)

\begin{tabular}{ll}
\hline Code & Participant (PS) \\
\hline Changing perspective & $1,5,11,15,20$ \\
Make friends, build relationships & $1,10,11,13,15$ \\
No expectations & $3,12,2,10$ \\
Being challenged outside of comfort zone & $3,8,10,13,16,18$ \\
To experience a range of emotions & $4,6,9$ \\
Make a positive and or meaningful contribution & $7,8,19$ \\
A different cultural experience & $8,11,17$ \\
Making a difference & $2,11,14$ \\
Life changing & $11,19,20$ \\
\hline
\end{tabular}

Findings from the focus group interviews, which relate to expectations of the immersion program, are presented in the Table 3. Each code is represented by the relevant focus group (1 or 2 ) followed by an individual participant (PS) number.

Table 3

Codes from Semi-structured Focus Group Interviews

\begin{tabular}{ll}
\hline Code & Group / Participant (PS) \\
\hline Experiencing a cultural immersion & $1: 8,1: 10 ; 1: 18 ; 2: 6$ \\
Building connections/relationships & $1: 15 ; 1: 8 ; 1: 18$ \\
Cultural exchange & $1: 7 ; 1: 8 ; 2: 12$ \\
Being challenged & $1: 8 ; 1: 18 ; 2: 12 ; 2: 6$ \\
Making a difference & $1: 10$ \\
Open mind/no expectations & $1: 18 ; 2: 6$ \\
Helping others & $1: 15 ; 1: 18$ \\
Personal change & $2: 6 ; 2: 12$ \\
\hline
\end{tabular}

Note. Focus group interviews: Group 1 (PS 7, 8, 10, 15, 18); Group 2: (PS 1, 6, 12, 13, 9)

\section{Findings and Discussion}

A synthesis of all three data sets is presented in the Table 4. Themes were established through data analysis, which involved identifying word repetitions. Three themes that emerged from the analysis: (1) Through cultural challenge, one is better able to understand oneself; (2) pedagogy is informed by intercultural immersions; (3) through intercultural experiences, one is able to build relationships with others. 
Table 4

Pre-Immersion Expectations

\begin{tabular}{|c|c|c|}
\hline Category & Codes & Theme \\
\hline $\begin{array}{l}\text { Personal } \\
\text { Expectations: }\end{array}$ & $\begin{array}{l}\text { Make a positive or meaningful contribution; helping } \\
\text { others; making a difference; form a different } \\
\text { perspective on life; being challenged; a once-in-a- } \\
\text { lifetime experience; life changing; stepping outside of } \\
\text { comfort zone; experience a range of emotions; } \\
\text { challenge personal values; grow as an individual; } \\
\text { appreciation and gratitude; privilege and } \\
\text { responsibility; making friends and forming } \\
\text { relationships; broaden knowledge and understanding. }\end{array}$ & $\begin{array}{l}\text { Through intercultural } \\
\text { experiences, one is better } \\
\text { able to understand } \\
\text { oneself. }\end{array}$ \\
\hline $\begin{array}{l}\text { Professional } \\
\text { Expectations: }\end{array}$ & $\begin{array}{l}\text { Inform me as a future teacher; enhance my skills; } \\
\text { change my view of teaching. }\end{array}$ & $\begin{array}{l}\text { Pedagogy is informed by } \\
\text { intercultural immersions. }\end{array}$ \\
\hline $\begin{array}{l}\text { Cultural } \\
\text { Expectations: }\end{array}$ & $\begin{array}{l}\text { A different cultural experience; unique experience; } \\
\text { once-in-a-lifetime experience; experiencing a cultural } \\
\text { immersion; reciprocal benefit; cultural exchange; } \\
\text { building connections/relationships. }\end{array}$ & $\begin{array}{l}\text { Through intercultural } \\
\text { experiences, one is able to } \\
\text { build relationships with } \\
\text { others. }\end{array}$ \\
\hline
\end{tabular}

\section{Personal Expectations: Through Intercultural Experiences, One is Better Able to Understand Oneself}

Personal expectations were determined, through the analysis, to be self-serving and were identified by participants in statements using personal pronouns (e.g., "I") or the word "students." Other indicators of expectations deemed personal were phrases that included specific words (i.e., "expect," "would like," "want to," "my/an expectation is ..."). Whereas it is expected that students would identify their personal expectations when asked about what they expected from the immersion, it is interesting to note how many did not use those words, denoting that they were thinking of something besides, or greater than, themselves when considering the question. However, to better understand the nature of the differences in students' expectations before embarking on the experience, it is important to explore what students reported.

An expectation that participants were joining the immersion to "make a difference" was a dominant thread in the data. "Making a difference" was perceived as a meaningful contribution; one that would be of benefit to others, as it sought to solve problems. As evident in the data, this was half of the social exchange, in that students also benefit, even if only in feeling good about making a difference. One student put it this way, "Students want to help the people in need; they see a problem and want to help be a part of making a difference" (PS 6). Another student said, "I think people choose to participate in programs to ultimately assist communities in need. Students are able to contribute to society in a multitude of meaningful ways whilst also interacting and working with other like-minded people" (PS 1). These responses, reminiscent of others, illustrate that many participants felt strongly about the desire to serve, but they also that they wanted to be a part of something greater than what they could accomplish alone. Participant responses were all centred on altruistic reasons.

Flanagan et al. (2015) found that service in communities, whether mandated by an institution or freely chosen, served to bolster connections and foster bridging social capital. Bridging social capital is 
illustrated in comments such as "working with like-minded people" (PS 1). This concept was also picked up by other participants. The following comment exemplifies this more than others':

I have expectations to build relationships with the people that I work with, and these friendships will last beyond the time we have in Kenya. As we all share similar interests and passions, I believe strong connections can be made in such a new situation that we are immersed in to together. (PS 5)

Also emerging from the data was an expectation that social capital would be further fostered once the participants were in the host country. Although there was a strong expectation regarding this among the group members, some participants realized that this concept stretched further than the group of volunteer students, denoting a more sophisticated view of building social capital beyond the immediate group. For example, "I am looking forward to meeting the local community and connecting with the students. I am really looking forward to immersing into their culture and staying with other students with local families" (PS 10). By recognizing that social capital extends beyond the immediate group, this articulation recognizes that social capital and intercultural competence are integral components of living and interacting effectively in diverse environments (Lucero, 2017).

Bolstering connections and building social capital can be attributed in part to the notion of social obligation, which was expressed in this study through a desire or the expression of a responsibility to serve. Because this immersion was promoted as a service-learning experience, it was very common to see the word "service" in many responses. It is difficult to say whether participants would have seen their immersion as service if it was not promoted as such, but either way, it provides insight into participants' expectations. What is more important is that students' expectations are aligned with the aims of the program. One student noted:

I think that service-learning programs are attractive as they provide an experience that is truly unique and different from the everyday, privileged, Western world that we live in. I believe that, as fortunate humans, we hold an innate responsibility to help those in need. (PS 3)

Another student put it this way, "I am aware that we live an extremely privileged life with an abundance of opportunities and potential. With this potential is a responsibility to strive to help; I wish to help" (PS 16). The idea of privilege and giving were prominent in many responses. Embedded in these statements, and in social obligation theory itself, is an almost guilt-like quality, perhaps exacerbated by the nature of a Catholic educational environment. Although the religious affiliation of the participants was not part of this research, the nature of Catholic educational principles at a Catholic university are embedded in every aspect of the social and academic experience, and therefore could be expected to be exemplified in the responses and actions of participants.

The connection between social obligation and having an awareness of others' circumstances also came through strongly in the data. Again, we see the desire or need to help those who are perceived to be less fortunate, and from a position of privilege, the yearning to serve. One student who mentioned this also mentioned a feeling of regret if she did not apply:

You always hear about those less fortunate, and I feel like this is the perfect opportunity for me to actually put words into actions and do something that would benefit someone else. To be in a position to be able to do something for someone else, especially something as life changing as the Kenya Trip, would be an amazing experience, and I know I would regret it if I didn't apply. (PS 19)

Although situated in a power imbalance, the above comments allude to the concept of empathy-the sense is that empathy, or at the very least, sympathy-played a part in participants' motivation to participate. Empathy, defined as a seeking to understand other people's perspectives (Preston \& de Waal, 2002; see also Gallese, 2003), was common in responses, especially when coupled with relationship building. It was recognized that through relationships with others, empathy can be enhanced. One student put it this way, "Without the relationship or understanding, then empathizing is so much harder. If you just go in there and try and run the show ... if you don't try and empathize with them or see where they are coming from, then it's much harder to have a relationship" (PS 8). Relationships allow opportunities to build mutual understanding - the understanding that acknowledges that making a difference, although 
usually positively construed, can also be negative. "It's seeking to understand; ... not just coming in and doing your own thing but listening and talking and needing to understand what is actually needed" (PS 20).

Another thread that regularly appeared in participant comments was "challenge." Participants viewed the immersion as a challenge; it was going to require them to step outside their comfort zones, their own lived experiences, or their known reality. Embedded in the comments that mentioned challenge was an expectation that the experience would lead to personal transformation. As one student said, "[It means] to be pushed to come out of your shell and put yourself into unusual and challenging situations. To have an experience that will develop confidence and wisdom, which you can use to continue to develop your own understandings and beliefs" (PS 17). It can be seen in this comment that participants recognized the limits of their own lived experience and were seeking a means to build dispositions that they may not be able to build in their own environments. It also required them to reflect on their own value system, as another student noted: "My expectation is that the Kenya immersion will change and challenge my values and perspectives on things such as my quality of life and my appreciation for things that I take for granted" (PS 6). Each of these comments and responses suggests a desire to learn, a recognition of oneself in one's own context, and the limitations of that context to develop deep understandings of the otherspecifically the "cultural other."

The following quote reflects a deeper, more holistic expectation of the challenge:

I am expecting to be pushed outside of my comfort zone. Have my own beliefs and skills challenged, [and] develop a better understanding of myself as a teacher and others around me.

This Kenya immersion is going to be an eye-opening experience, and I look forward to being stretched emotionally, physically, and spiritually. (PS 10)

Recognition of self and desire, as well as the willingness to learn, is the last of the common threads within the "personal expectation" theme. As mentioned previously, when discussing service, one needs to remain cognizant that the trip was promoted to students as a service-learning immersion. Therefore, one expected to see the words "service" and "learning" appearing in responses. However, not all comments that illustrated a willingness to learn included those words, which helps validate the statements as true representations of students' expectations. One student noted, "I chose to participate in the program with a curiosity and willingness to deepen my understanding of the world, to see how people from such different backgrounds and experiences live, and to deepen my empathy for others" (PS 4). In this comment we see a desire to learn and develop skills, which illustrates an understanding of oneself and one's strengths and areas of development. Curiosity is also reflected in the statement above, which is often a precursor for learning. In another statement, curiosity and lack of understanding and experience was noted as a major reason for participating:

One of the primary reasons I chose to participate in this program is because I realize that, in our Western society in particular, we can be completely separated from the hardships of people who struggle to feed their families on the other side of the world. I want to see firsthand the conditions in which people survive with next to nothing. I don't want to choose to be blind. (PS 4) This statement is illustrative of the desire to learn, to choose not to be blind to the world around us.

Although learning was the last thread of this theme, there was another aspect of student comments worth noting. Some students chose to not have expectations prior to the immersion; they wanted to go in with an open mind and allow the experience to happen, without any preconceived notions of what they might gain from it. For example,

I believe it is hard to imagine what to expect. You can have some ideas about what you think it is going to be like, and for me I have thoughts about what I imagine my Kenyan experience to be; but I also think, in reality, it will be nothing like what I imagine. I don't think you can know what to expect; that's why I believe you have to be as open-minded as possible to all situations as it is nothing what I have experienced before. (PS 12)

While many students noted that they did not have specific expectations or that they did not want to have them, these same students also noted particular aspects of the theme already mentioned, such as challenge. As one student said, 
To be honest, I have tried to avoid making any expectations of the trip. This includes expectations of how I will react to the experience. I guess the only expectation I have is that I will be confronted and challenged in a way I have never been before. (PS3)

The personal expectations of participants for the immersion were diverse; however, commonalities were exemplified in their comments and reflected social obligation theory.

From a desire to give back, to be challenged, to build relationships and learn from those relationships, participants articulated both a desire to make a difference and a responsibility to do so. The desire to make a difference, accompanied by the responsibility to do so, is congruent with altruistic motives. For many students, they were about to embark on an experience that was going to challenge their own sense of self and other, and they expected to change as a result of that challenge. Their articulation of what that challenge could represent, and how it might change them, included aspects of their own cultural selves such as their values and beliefs. Additionally, they expected it to challenge their own positions of privilege and what that actually meant in the wider world. Embedded within all these ideas, though, is a desire to learn: that they would go to Kenya; they would build social capital through relationships with one another and with members of the host community; that they would allow themselves an opportunity to build empathy as an inherent disposition.

\section{Professional Expectations: Pedagogy is Informed by Intercultural Immersions}

Professional expectations were deemed any statements that included the words "teach," "teacher," "education," "learning," "theory," "practice," "children," and "Aberdare Ranges Primary School." Whilst the word "pedagogy" was not specifically used by participants, their responses are indicative of aspects of teacher training that one in the profession would expect students to reflect on as part of teaching practice. Through a pedagogy lens, this immersion was partly centered on the educational philosophy of experiential learning (Gyles \& Eyler, 1994; Stanton et al., 1999). Participants were placed in classrooms in Kenya, which provided an opportunity, through experience, to improve their pedagogy and to reflect on their own teaching practice.

The philosophy of experiential learning is one that is understood by preservice teachers as leading to positive outcomes. The articulation of this was summed up as follows:

I believe students will benefit in terms of development, growth, and achievement. It engages you in active learning, allowing you to achieve learning goals. It translates theory into practice and ideas into actions. In helping those who are in need, you are enhancing your skills in teaching and widening your perceptions. (PS 9)

This particular comment demonstrates an understanding of another aspect of pedagogy, that of skill development. The immersion provided an opportunity to enhance or develop teaching skills. The development of requisite skills is a central tenet of teacher training programs. Logically, the mentioning of skills was common throughout participant responses.

The idea of being thrown into the deep end, needing to be confident and flexible and resilient, are skills and experiences that I feel I need to experience and further develop to be a competent teacher. I feel by going, I will further develop these skills. (PS 6)

The idea of being "thrown into the deep end" in order to be able to develop skills towards becoming a competent teacher is reminiscent of the personal expectation that participants were going to be challenged. From a professional perspective, participants, who were all conversant in English, were now in an environment where Kiswahili was the native language and the language of classroom instruction. Interestingly, rather than perceiving this as a deficit, participants viewed this as a positive challenge: "I want to be immersed in an environment where language barriers are a challenge, so I can learn strategies to overcome these barriers, which I can use later with EAL/D (English as an Additional Language or Dialect) students in my classroom" (PS 16). This participant viewed language as cultural awareness, which is one aspect of intercultural competence.

There were a number of threads in professional expectations that were similar to those for personal expectations. Through experiential learning, the participants were in a position to develop empathy. The 
development of empathy as a professional expectation is bounded in and by the practice of teaching. One student said,

I thought being a part of this project will give me an opportunity to put myself in other people's shoes; look at teaching from a different perspective; and get a real, hands-on experience that will possibly change the way I view teaching and life. (PS1)

This comment indicates the expectation that the immersion was going to be transformational. The idea of changing one's view of teaching or of life is grounded in the theory of transformative learning. Transformative learning theory focuses on how individuals learn to negotiate confronting or unfamiliar situations in order to evaluate their own or others' purposes; critically evaluate their own and others' values; and/or understand the complexity of social structures through the values of tolerance, social justice, and equity (Mezirow, 2000). Immersion experiences as transformational learning place participants in situations or circumstances that lead to changes in perspective:

I expect that these experiences will help me grow into the well-rounded, honest teacher that I aspire to be; who is able to share an experience like this with students to teach them about abundance, displacement, what it means to be grateful and the importance of school and education. (PS 9)

Another aspect of both personal and professional expectations was that of participants' notions of privilege. However, rather than being a sense of privilege, which is centered on a power imbalance, this privilege was linked to their professional responsibility. Essentially, with privilege comes responsibility, which could be used to both inform and empower others.

Kenya will most definitely give me the opportunity to continue my eagerness and enthusiasm to become the best teacher that I can be, and enhance my educational skills with real-life experiences. In my teaching career, my philosophy will always be to encourage an appreciation and value for the world around us. Being part of the Kenya Immersion will give me this value to pass on to students in their daily lives. (PS 17)

As preservice teachers, participants acknowledged the potential of experiential learning to allow them to connect theory to practice - practice that would be enhanced by being placed in an environment that was perceived as professionally challenging. Such a challenge was viewed positively, being one that would present an opportunity to develop their pedagogy, ultimately allowing them to be more culturally and appropriately responsive to diversity. Further, participants acknowledged that the immersion would allow for empathy to be developed, which would facilitate a deeper understanding of both teaching and, more broadly, the notion of education as a driver of social change.

\section{Cultural Expectations: Through Intercultural Experiences, One is Able to Build Relationships With Others}

Cultural expectations were deemed any statements that included the following words: "culture," "Africa," "Kenya," and "homestays." Many of the key ideas that emerged from both the personal and professional expectations were synthesized in participants' cultural expectations of the immersion. Participants' expectations that personal and professional perspectives would change by connecting knowledge and developing empathy was expressed as a desire or expectation to experience a culturally different way of life. One student said, "I think having the opportunity to immerse yourself in a community within a culture completely different to your own is such an exciting opportunity to pass up if you are open to learning and experiencing other communities and cultures" (PS 9). The openness to learning and the desire to experience different cultures and communities would facilitate personal and professional growth.

A significant component of the immersion program that would ideally enhance the experience of a different way of life, was that all participants were placed with local families in homestay accommodation, which was relished by participants. One participant said,

I am most looking forward to being part of the culture. Really immersing into their culture. I am so happy that we are staying with families in the village, as I really think that if we weren't doing that, it wouldn't make such a difference. (PS 12) 
Learning about the culture of the "other" by being immersed in homestay accommodation and the desire to view the world through a different cultural lens, whilst building cultural knowledge, was reflected by the following comment: "I honestly love to experience different cultures. I believe that interacting with people around the world teaches you how to live in different ways and see the world through their eyes, through their values and spirituality" (PS 8).

Homestays enable an understanding of culture through the formation of relationships, which are the center of human interaction. This understanding was exemplified in one student's comment: "I am most looking forward to meeting the family I will be staying with and the children at the school. I'm really excited to spend time with them, get to know them, and form a relationship and learn more about their culture and community" (PS 4).

In further attempting to understand the "cultural other," there emerged a dichotomy between participants' own perceived culture and that of the "cultural other"; one that viewed others through the lens of difference. This difference is viewed in the context of privilege - privilege that both represents a power imbalance and allows for personal and professional change:

I am most looking forward to observing and being connected to a vastly different world. I feel that it is going to have an immense effect on my engrained Western values and expectations. I am also looking forward to teaching ESL (English as a Second Language) students and making strong connections with children and the families I stay with. I can't wait to learn about Kenyan customs and way of life, and this immersive experience will allow me to do that. (PS 19)

The degree of impact that the immersion would have on participants" "Western values" would, as Yunkaporta (2009) suggested, require participants to leave behind their own limiting beliefs before they engage with the "cultural other." One student's comment reflected this: "The idea of escaping the normal Western way of living and experience things and the lifestyle of others; I want to be able to connect with others from a very different background on an honest and human level" (PS 10).

These themes are not mutually exclusive. As can be seen in many of the participant statements above, these three themes work in conjunction with one another to illustrate the varying expectations of students before this immersion. One student articulated all three themes explicitly in her comment:

You always hear about those less fortunate, and I feel like this is the perfect opportunity for me to actually put words into actions and do something that would benefit someone else. I look at my life and realize I have been given so many wonderful opportunities to get to where I am; and sometimes we don't even realize how fortunate we are and how we can take these things for granted. I have been given many opportunities that have allowed me to reach my goal in life to become a teacher. I feel that it would be such a rewarding experience to extend what I've learnt and use my teachings to help those less fortunate. I am not only hoping to make a difference in these children's lives; I think it would be something I would like to share with a school I'm working with in Australia. (PS 11)

Cultural expectations centered on the idea that the immersion would offer an opportunity to experience a different way of life. To be immersed in a culture by staying with local families allowed relationships to be built, empathy to be developed, and cultural knowledge to be enhanced. It also provided an opportunity for participants to reflect on themselves as cultural beings.

\section{Conclusion}

International immersion experiences are often aimed at developing global awareness, developing shared understandings, and collaboratively responding to social issues. Through the lived experience of being immersed in a culture that is different from their own, participants who volunteer for such programs have an opportunity to learn more about themselves personally, professionally, and culturally. Expectations of participants in this particular immersion were largely centered on seeking to understand themselves (egoistic) through participation in an altruistic experience connecting with one another and with members of the host community. Such a connection would foster personal transformation and professional learning. 
The altruistic need to make a difference to the lives of others was a strong expectation for participants in the immersion program. Participants most looked forward to engaging with the "cultural other" so as to better understand themselves as cultural beings as well as to further respect and engage with the cultural plurality of a globalized world. This engagement was fostered through homestay accommodation and working with children and the community at Aberdare Ranges Primary School. The expectation of engaging with others required participants to step outside their own comfort zones. This stepping out was viewed by many as a challenge - a challenge centered on the perceived difference between themselves and the culture and community to which they were traveling.

Students' expectations of the experience mirrored closely the goals of the program, which was designed to enhance preservice teachers' knowledge and understanding of the cultural plurality of our globalized world. Such a plurality will become evident as the participants engage with student diversity in the classrooms where they will ultimately teach-classrooms that will require them to demonstrate the requisite skills and dispositions reflective of intercultural competence.

The implications of this research include a better understanding of internationalization programs in higher education; greater clarity as to the effects of international immersion programs on participants' personal and professional dispositions towards education; especially the education of students who are culturally and linguistically diverse. Lastly, this study suggests the potential for longitudinal research regarding the impact of intercultural immersion programs on participants' practice when they become full members of the teaching profession.

\section{References}

Altbach, P. G., \& Knight, J. (2007). The internationalization of higher education: Motivations and realities. Journal of Studies in International Education, 11(3-4), 290-305.

Australian Bureau of Statistics. (2016). 2016 census quickstats. https://quickstats.censusdata.abs.gov.au/census_services/getproduct/census/2016/quickstat/036

Australian Institute for Teaching and School Leadership. (2011). www.aitsl.edu.au

Bamber, P., Lewin, D., \& White, M. (2018). (Dis-) Locating the transformative dimension of global citizenship education. Journal of Curriculum Studies, 50(2), 204-230.

Batson, C. D. (1997). Self-other merging and the empathy-altruism hypothesis: Reply to Neuberg et al. Journal of Personality and Social Psychology, 73(3), 517-522. https://doi.org/10.1037/00223514.73.3.517

Batson, C. D. (1998). Altruism and prosocial behavior. In D. T. Gilbert, S. T. Fiske, \& G. Lindzey (Eds.), Handbook of social psychology (4th ed., Vol. 2, pp. 282-315). McGraw-Hill.

Braun, V., \& Clarke, V. (2019). Reflecting on reflexive thematic analysis. Qualitative Research in Sport, Exercise and Health, 11(4), 589-597. https://doi.org/10.1080/2159676X.2019.1628806

Butin, D. W. (2003). Of what use is it? Multiple conceptualisations of service learning within education. Teachers College Record, 105(9), 1674-1692.

Campus Compact. (2002). Membership. http://www.compact.org

Centre for Education Statistics and Evaluation. (2018). Statistics. https://www.cese.nsw.gov.au/

Chareka, O., Leyte, G., \& Mills, A. (2010). Let us walk the talk: Successes and struggles in implement global education as a regular course at university level. Policy \& Practice: A Development Education Review, 10, 120-126.

Clary, E. G., \& Snyder, M. (1999). The motivations to volunteer: Theoretical and practical considerations. Current Directions in Psychological Science, 8(5), 156-159.

Clayton, P. H., Bringle, R. G., \& Hatcher, J. A. (2012). Research on service learning: Conceptual frameworks and assessment (Vol. 1). Stylus Publishing.

Cole, J. R. (1994). The research university in a time of discontent. Johns Hopkins University Press.

Cooper, C. M. (2017). Transformation through disorientation: A narrative approach to perspective change in study abroad contexts. Drexel University. 
Curtis, T., \& Ledgerwood, J. R. (2018). Students' motivations, perceived benefits and constraints towards study abroad and other international education opportunities. Journal of International Education in Business, 11(1), 63-78. https://doi.org/10.1108/JIEB-01-2017-0002

Darling-Hammond, L. (2010). Teacher education and the American future. Journal of Teacher Education, 61(1-2), 35-47. https://doi.org/10.1177/0022487109348024

Eby, J. (1998). Why service-learning is bad. https://www1.villanova.edu/content/dam/villanova/artsci/servicelearning/WhyServiceLearningIsBad. pdf

Finkelstein, M. A., Penner, L. A., \& Brannick, M. T. (2005). Motive, role identity, and prosocial personality as predictors of volunteer activity. Social Behavior and Personality: An International Journal, 33(4), 403-418.

Fitch, R. T. (1987). Characteristics and motivations of college students volunteering for community service. Journal of College Student Development, 28(5), 424-431.

Flanagan, C. A., Kim, T., Collura, J., \& Kopish, M. A. (2015). Community service and adolescents' social capital. Journal of Research on Adolescence, 25(2), 295-309.

Gage III, R. L., \& Thapa, B. (2012). Volunteer motivations and constraints among college students: Analysis of the volunteer function inventory and leisure constraints models. Non-profit and Voluntary Sector Quarterly, 41(3), 405-430.

Gallese, V. (2003). The manifold nature of interpersonal relations: The quest for a common mechanism. Philosophical Transaction of the Royal Society B, 358(1431), 517-528. https://doi.org/10.1098/rstb.2002.1234

Gay, G. (2010). Culturally responsive teaching: Theory, research, and practice. Teachers College Press.

Giles Jr., D. E., \& Eyler, J. (1994). The theoretical roots of service-learning in John Dewey: Toward a theory of service-learning. Michigan Journal of Community Service Learning, 1(1), 77-85.

Hill, J., Walkington, H., \& France, D. (2016). Graduate attributes: Implications for higher education practice and policy: Introduction. Journal of Geography in Higher Education, 40(2), 155-163.

Hoy, W. K., \& Miskel, C. G. (1991). Educational administration: Theory, research, and practice (4th ed.). McGraw-Hill.

Lucero, A. (2017). Social capital and intercultural communication: Exploring trust, diversity and engagement in neighborhoods [Thesis, Concordia University, St. Paul]. Digital Ccommons @ CSP. https://digitalcommons.csp.edu/cup_commons_grad_commpsych/11

Mangram, J., \& Watson, A. (2011). Us and them: Social studies teachers' talk about global education. Journal of Social Studies Research, 35(1), 95-116.

Martin, M. W. (1994). Virtuous giving: Philanthropy, voluntary service, and caring. Indiana University Press.

Merriam, S. B. (2002). Introduction to qualitative research. In S. B. Merriam (Ed.), Qualitative research in practice: Examples for discussion and analysis (2nd ed., pp. 3-18). Jossey-Bass.

Meyer-Lee, E., \& Evans, J. (2007). Areas of study in outcomes assessment. In M. C. Bolen (Ed.), A guide to outcomes assessment in education abroad (pp. 61-70). The Forum on Education Abroad.

Mezirow, J. (2000). Learning as transformation: Critical perspectives on a theory in progress. JosseyBass.

Miller, J. (2015). Classroom strategies for teachers and EAL students. In J. Hammond \& J. Miller (Eds.). Classrooms of possibility: Supporting at-risk EAL students (pp.1-10). Primary English Teachers Association.

Miller, L. E., \& Grush, J. E. (1988). Improving predictions in expectancy theory research: Effects of personality, expectancies, and norms. Academy of Management Journal, 31(1), 107-122. https://doi.org/10.5465/256500

Moloney, R., \& Saltmarsh, D. (2016). 'Knowing your students' in the culturally and linguistically diverse classroom. The Australian Journal of Teacher Education, 41(4).

http://dx.doi.org/10.14221/ajte.2016v41n4.5 
Mooney, L. A., \& Edwards, B. (2001). Experiential learning in sociology: Service learning and other community-based learning initiatives. Teaching Sociology, 29(2), 81-194. https://doi.org/10.2307/1318716

Mounter, C. T. (1985). A study of the degree of success of a volunteer program based on the motivations of volunteer and perceptions of these by agents [Unpublished doctoral dissertation, University of Georgia].

Musick, M. A., \& Wilson, J. (2007). Volunteers: A social profile. Indiana University Press.

Parnell, D. (1990). Dateline 2000: The new higher education agenda. American Association of Community and Junior Colleges.

Phillips, M. (1982). Motivation and expectation in successful volunteerism. Journal of Voluntary Action Research, 11(2-3), 118-125. https://doi.org/10.1177/089976408201100213

Preston, S. D., \& de Waal, F. B. M. (2002). Empathy: Its ultimate and proximate bases. Behavioral and Brain Sciences, 25(1). https://doi.org/10.1017/S0140525X02000018

Roose, D. (2001). White teachers' learning about diversity and "otherness": The effects of undergraduate international internships on subsequent teaching practices. Equity and Excellence in Education, 34(1), 43-49. https://doi.org/10.1080/1066568010340106

Ryan, R. L., Kaplan, R., \& Grese, R. E. (2001). Predicting volunteer commitment in environmental stewardship programmes. Journal of Environmental Planning and Management, 44(5), 629-648. https://doi.org/10.1080/09640560120079948

Shye, S. (2010). The motivation to volunteer: A systemic quality of life theory. Social Indicators Research, 98(2), 183-200. https://doi.org/10.1007/s11205-009-9545-3

Siwatu, K. O. (2007). Preservice teachers' culturally responsive teaching self-efficacy and outcome expectancy beliefs. Teaching and Teacher Education, 23(7), 1086-1101. https://doi.org/10.1016/j.tate.2006.07.011

Steers, R. M., \& Porter, L. W. (1983). Motivation and work behavior (3rd ed.). McGraw-Hill.

Stanton, T. K., Giles Jr., D. E., \& Cruz, N. I. (1999). Service-learning: A movement's pioneers reflect on its origins, practice, and future. Jossey-Bass.

Stoecker, R.,Tyron, E. A., \& Hilgendorf, A. (Eds.). (2009). The unheard voices: Community organizations and service learning. Temple University Press.

Villegas, A. M., \& Lucas, T. (2002). Preparing culturally responsive teachers rethinking the curriculum. Journal of Teacher Education, 53(1), 20-32. https://doi.org/10.1177/0022487102053001003

Walters, L. M., Garii, B., \& Walters, T. (2009). Learning globally, teaching locally: Incorporating international exchange and intercultural learning into pre-service teacher training. Intercultural Education, 20(Suppl. S1-2), S151-S158. https://doi.org/10.1080/14675980903371050

Whaley, A. L., \& Davis, K. E., (2007). Cultural competence and evidence-based practice in mental health services: A complementary perspective. American Psychologist, 62(6), 563-574. https://doi.org/10.1037/0003-066X.62.6.563

Yunkaporta, T. (2009). Aboriginal pedagogies at the cultural interface [Professional doctorate (research) thesis, James Cook University]. ResearchOnline@JCU. http://eprints.jcu.edu.au/10974

Zeichner, K. (2010). Rethinking the connections between campus courses and field experiences in college- and university-based teacher education. Journal of Teacher Education, 61(1-2), 89-99. https://doi.org/10.1177\%2F0022487109347671

Zimmer, L. (2006). Qualitative meta-synthesis: A question of dialoguing with texts. Journal of Advanced Nursing, 53(3), 311-318. https://doi.org/10.1111/j.1365-2648.2006.03721.x 


\begin{abstract}
About the Authors
Julie Maakrun is a senior lecturer in the School of Education at the University of Notre Dame, Australia. Sean Kearney is an associate professor in the School of Education at the University of Notre Dame, Australia.
\end{abstract}

Correspondence concerning this article should be addressed to Julie Maakrun at jmaakrun@hotmail.com. 